\title{
A machine learning based approach for efficient safety evaluation of the high speed train and short span bridge system
}

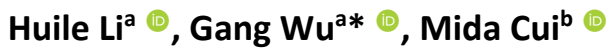 \\ ${ }^{a}$ Key Laboratory of Concrete and Prestressed Concrete Structures of the Ministry of Education, National and Local Joint Engineering \\ Research Center for Intelligent Construction and Maintenance, Southeast University, Nanjing 211189, China. Email: huile.li@seu.edu.cn, \\ g.wu@seu.edu.cn \\ b School of Civil Engineering, Southeast University, Nanjing 211189, China. Email: m.cui@seu.edu.cn \\ * Corresponding author
}

https://doi.org/10.1590/1679-78256238

\begin{abstract}
The dynamic responses of the high-speed railway bridge under the train passage can greatly affect the safety of the entire high-speed train and bridge system. Traditionally, these responses are obtained using either field measurement or numerical analysis. Both tools have their own limitations. For instance, the coupling dynamic train-bridge analysis is generally complicated and time-consuming. This paper proposes a novel machine learning based approach for efficient safety evaluation of the high speed train and short span bridge system. Artificial neural networks are established to map the complicated train-bridge system and to attain the critical bridge displacements. The proposed approach incorporates a complete numerical train-bridge system model to produce reliable data for the neural network training, considering multiple significant random features in the train-bridge system. Various neural network architectures are investigated and compared to find optimal ones that have considerable potentials in realizing online response prediction and safety evaluation. Although the proposed approach focuses on the high-speed train and short span bridge, the methodology is general and can also be applied to other scenarios associated with the vehicle-bridge systems.
\end{abstract}

\section{Keywords}

high-speed railway bridge, machine learning, train-bridge interaction, structural dynamic analysis, backpropagation neural network, safety assessment

\section{Graphical Abstract}
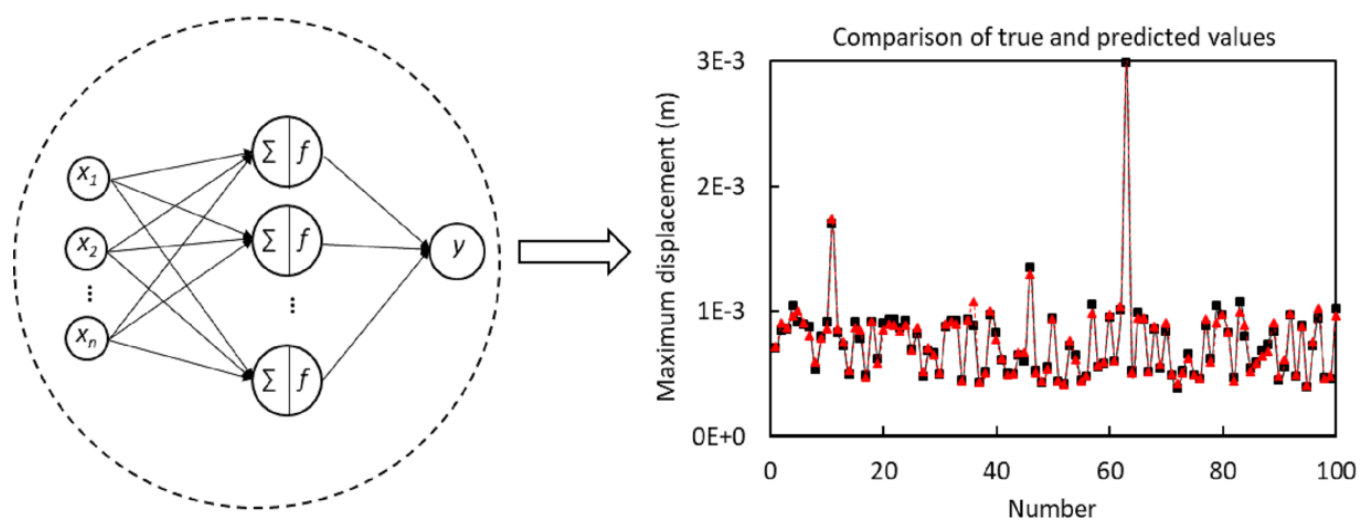

Received: August 24, 2020. In Revised Form: September 06, 2020. Accepted: September 07, 2020. Available online: September 08,2020 https://doi.org/10.1590/1679-78256238

(i) Latin American Journal of Solids and Structures. ISSN 1679-7825. Copyright @ 2020. This is an Open Access article distributed under the terms of the Creative Commons Attribution License, which permits unrestricted use, distribution, and reproduction in any medium, provided the original work is properly cited. 


\section{Introduction}

High-speed rails have become one of the most attractive means of transportation due to their many advantages including rapidity, safety, punctuality, and comfort, among others. The high-speed railway lines built across the word play a vital role in promoting the economic and social development. Bridges serve as the key infrastructures in the highspeed railway system. In particular, the short-span and simply-supported bridge is widely used to carry high-speed rails, thanks to its large stiffness, standardized construction, little maintenance and so on. The safety condition of the bridges tremendously affects the reliability of the entire high-speed railway system.

Dynamic responses of the bridge produced by the passing high-speed trains are regarded as important indices for evaluating the bridge operating condition (Galvín et al. 2018; Liu et al. 2009). Bridge displacement, as an indication of structural health condition, provides one of the most valuable information for the assessment of global bridge behavior such as degree of damage, structural stiffness, and bearing capacity (Moreu et al. 2015). Furthermore, deformation of the high-speed railway bridge has great impact on track geometries and therefore running safety of the train (Gou et al. 2019). Nevertheless, the in-situ measurement campaign of bridge displacement, either using contact-type techniques (Ozdagli et al. 2018; Xia et al. 2003) or noncontact-type ones (Ribeiro et al. 2014; Feng and Feng 2018), can be adversely affected by the bridge site, environmental condition such as illumination, implementation cost, and data post-processing, among others.

A dynamic train-bridge system model can be considered to obtain the abovementioned response. The system model generally consist of a multiple degrees-of-freedom (DOFs) vehicle model, a finite element (FE) based bridge model, and a wheel-rail interaction model (Yang et al. 2004; Antolín et al. 2013; Salcher et al. 2016). Additionally, the train-bridge system is subjected to significant randomness arising from the bridge structure and train vehicle, as well as track irregularities (Li et al. 2016). Simplified analysis models without considering track irregularities, such as moving load model and vertical spring-mass model enabling the Monte-Carlo simulation were employed to facilitate the evaluation of the bridge dynamic response in fast and probabilistic manners (Rocha et al. 2012; Rocha et al. 2014). Probabilistic train-bridge coupling dynamic analysis only considering the random excitations associated with track irregularities was realized in several studies. For example, the pseudo-excitation method was used to compute the random dynamic responses of the train-bridge system in Jin et al. (2015). Yu et al. (2016) adopted the probability density evolution method to achieve random vibration analysis. Despite the fact that the sophisticated system models is able to yield accurate responses associated with the train vehicle and bridge structure (Li et al. 2015), the process of developing and solving these models is usually complicated and prohibitive to practical engineers and sometimes even researchers. This prevents the train-bridge dynamic analysis from being widely used by professionals and fully included in associated codes to a certain extent (Xia et al. 2018).

Machine learning $(\mathrm{ML})$ based methods have recently demonstrated increasing potentials and therefore gained more and more attractions in structural dynamic analysis and bridge assessment associated with vehicle loads. Lu et al. (2017) adopted support vector regression to fit a response function and avoid time-consuming FE analysis in fatigue reliability evaluation of steel bridges under moving truck loads. Deng et al. (2020) utilized the support vector machines (SVM) to construct the relationship between measured traffic data and fatigue damage accumulation in steel hangers of suspension bridge that is calculated trough FE analysis. The SVM method has also been employed to effectively simulate the fatigue damage in coastal slender bridges considering the combination of wind, wave, and vehicle loads (Zhu and Zhang 2018; Lu et al. 2020). In addition, several studies have been conducted incorporating artificial neural networks (ANNs), as one of the most commonly used algorithms in ML. The neural network was trained for damage detection of simply-supported bridge with the train-induced response obtained from FE models being the input (Shu et al. 2013; Neves et al. 2017). Yan et al. (2019) adopted the back-propagation ANN (BP-ANN) to correlate the vehicular overloading and fatigue damage index with computed data. Han et al. (2019) realized the prediction of bridge acceleration using the nonlinear autoregressive exogenous ANNs with a simplified quarter-vehicle model and FE bridge model. Moon et al. (2019) presented a predictive method for vertical displacement of highway bridges based on ANNs, in which the bridge strain data produced by numerical analysis considering the measured vehicle distribution serves as the input of the network. Overall, the study focusing on the ML based approach to the prediction of bridge dynamic response and further evaluation of bridge condition due to vehicle loads is still very limited.

The objective of this paper is to present a novel ML based approach for efficient evaluation of dynamic response and further safety condition of short span bridges widely used in the high-speed railways. To the best of the authors' knowledge, the study reported should be the first one that applies the ANN method to a complete and real train-bridge system for the purposes of structural dynamic analysis and safety assessment. The reminder of the paper is structured as follows. In section 2, a complete high-speed train and bridge system model reflecting the real mechanical behaviors is established and elaborated. Section 3 presents the ML based methodology in a detailed manner. Comparison and 
selection of various neural network architectures are conducted based on which efficient prediction and evaluation of the bridge dynamic responses are achieved in section 4. Finally, conclusions drawn from the investigation are presented in section 5 .

\section{Numerical train-bridge system model}

A coupled numerical model of the high-speed train and bridge system is established in this section. This system model consists of the train model, bridge model, and wheel-rail interaction model. The train-bridge system equation of motion is formulated and solved utilizing both ANSYS (ANSYS Inc, 2014) and MATLAB (MATLAB 2015) software.

\subsection{Train model}

A high-speed train can typically be composed of several four-axle vehicles. Each train vehicle consists of three kinds of main components. They are one car-body, two bogies, and four wheel-sets, which can be treated as rigid-bodies. Furthermore, DOFs associated with the rigid-body movements of the car-body are sway $Y_{c}$, rolling $\vartheta_{c}$, yawing $\Psi_{c}$, floating $Z_{c}$, and pitching $\varphi_{c}$. Similarly, DOFs of each bogie are sway $Y_{b}$, rolling $\vartheta_{b}$, yawing $\psi_{b}$, floating $Z_{b}$, and pitching $\varphi_{b}$, and those of each wheel-set are sway $Y_{w}$, rolling $\vartheta_{w}$, yawing $\psi_{w}$, and floating $Z_{w}$. Therefore, a total of 31 DOFs are considered in this study in order to simulate the motion of a real high-speed train vehicle. In addition, the bogies are connected with the car-body and wheel-sets through the secondary and primary suspension systems, respectively. Both two suspension systems are modeled as springs and dashpots (see Fig. 1). Parameters of a typical high-speed train used in China are adopted in the present analysis and reported in Table 1.

Table 1 Summary of the train parameters.

\begin{tabular}{|c|c|c|}
\hline Parameter & Value & Unit \\
\hline Mass of the car-body $\left(M_{c}\right)$ & $4 \times 10^{4}$ & $\mathrm{~kg}$ \\
\hline Moment of inertia of car-body around $x$-axis $\left(J_{c x}\right)$ & $1.84 \times 10^{6}$ & $\mathrm{~kg} \mathrm{~m}^{2}$ \\
\hline Moment of inertia of car-body around $y$-axis $\left(J_{c y}\right)$ & $5.06 \times 10^{5}$ & $\mathrm{~kg} \mathrm{~m}^{2}$ \\
\hline Moment of inertia of car-body around $z$-axis $\left(J_{C z}\right)$ & $1.92 \times 10^{6}$ & $\mathrm{~kg} \mathrm{~m}^{2}$ \\
\hline Mass of the bogie $\left(M_{g}\right)$ & $3.2 \times 10^{3}$ & $\mathrm{~kg}$ \\
\hline Moment of inertia of bogie around $x$-axis $\left(J_{g x}\right)$ & $3.2 \times 10^{3}$ & $\mathrm{~kg} \mathrm{~m}^{2}$ \\
\hline Moment of inertia of bogie around $y$-axis $\left(J_{g y}\right)$ & $6.8 \times 10^{3}$ & $\mathrm{~kg} \mathrm{~m}^{2}$ \\
\hline Moment of inertia of bogie around $z$-axis $\left(J_{g z}\right)$ & $7.3 \times 10^{3}$ & $\mathrm{~kg} \mathrm{~m}^{2}$ \\
\hline Mass of the wheel-set $\left(M_{w}\right)$ & $2.4 \times 10^{3}$ & $\mathrm{~kg}$ \\
\hline Moment of inertia of wheel-set around $x$-axis $\left(J_{w x}\right)$ & $1.21 \times 10^{3}$ & $\mathrm{~kg} \mathrm{~m}^{2}$ \\
\hline Moment of inertia of wheel-set around $z$-axis $\left(J_{w z}\right)$ & $1.21 \times 10^{3}$ & $\mathrm{~kg} \mathrm{~m}{ }^{2}$ \\
\hline Primary vertical spring stiffness $\left(k_{P V}\right)$ & $1.04 \times 10^{6}$ & $\mathrm{~N} / \mathrm{m}$ \\
\hline Primary lateral spring stiffness $\left(k_{P H}\right)$ & $3 \times 10^{6}$ & $\mathrm{~N} / \mathrm{m}$ \\
\hline Secondary vertical spring stiffness $\left(k_{s V}\right)$ & $2.4 \times 10^{5}$ & $\mathrm{~N} / \mathrm{m}$ \\
\hline Secondary lateral spring stiffness $\left(k_{S H}\right)$ & $4 \times 10^{5}$ & $\mathrm{~N} / \mathrm{m}$ \\
\hline Primary vertical damping $\left(c_{P V}\right)$ & $5 \times 10^{4}$ & $\mathrm{~N} \mathrm{~s} / \mathrm{m}$ \\
\hline Primary lateral damping $\left(C_{P H}\right)$ & 0 & $\mathrm{~N} \mathrm{~s} / \mathrm{m}$ \\
\hline Secondary vertical damping $\left(c_{S V}\right)$ & $6 \times 10^{4}$ & $\mathrm{~N} \mathrm{~s} / \mathrm{m}$ \\
\hline Secondary lateral damping $\left(c_{S H}\right)$ & $3 \times 10^{4}$ & $\mathrm{~N} \mathrm{~s} / \mathrm{m}$ \\
\hline Half distance between two wheel-sets $\left(d_{1}\right)$ & 1.25 & $\mathrm{~m}$ \\
\hline Half distance between two bogies $\left(d_{2}\right)$ & 8.68 & $\mathrm{~m}$ \\
\hline Half distance between two car-body couplers $\left(d_{3}\right)$ & 12.5 & $\mathrm{~m}$ \\
\hline Half span of the primary suspension system $\left(d_{4}\right)$ & 0.748 & $\mathrm{~m}$ \\
\hline Half span of the secondary suspension system $\left(d_{5}\right)$ & 0.978 & $\mathrm{~m}$ \\
\hline Wheel radius $\left(r_{w}\right)$ & 0.43 & $\mathrm{~m}$ \\
\hline Distance between the bogie and wheel-sets $\left(d_{6}\right)$ & 0.28 & $\mathrm{~m}$ \\
\hline Distance between the secondary suspension system and bogie $\left(d_{7}\right)$ & 0.14 & $\mathrm{~m}$ \\
\hline Distance between the car-body and the secondary suspension system $\left(d_{8}\right)$ & 1.7 & $\mathrm{~m}$ \\
\hline
\end{tabular}



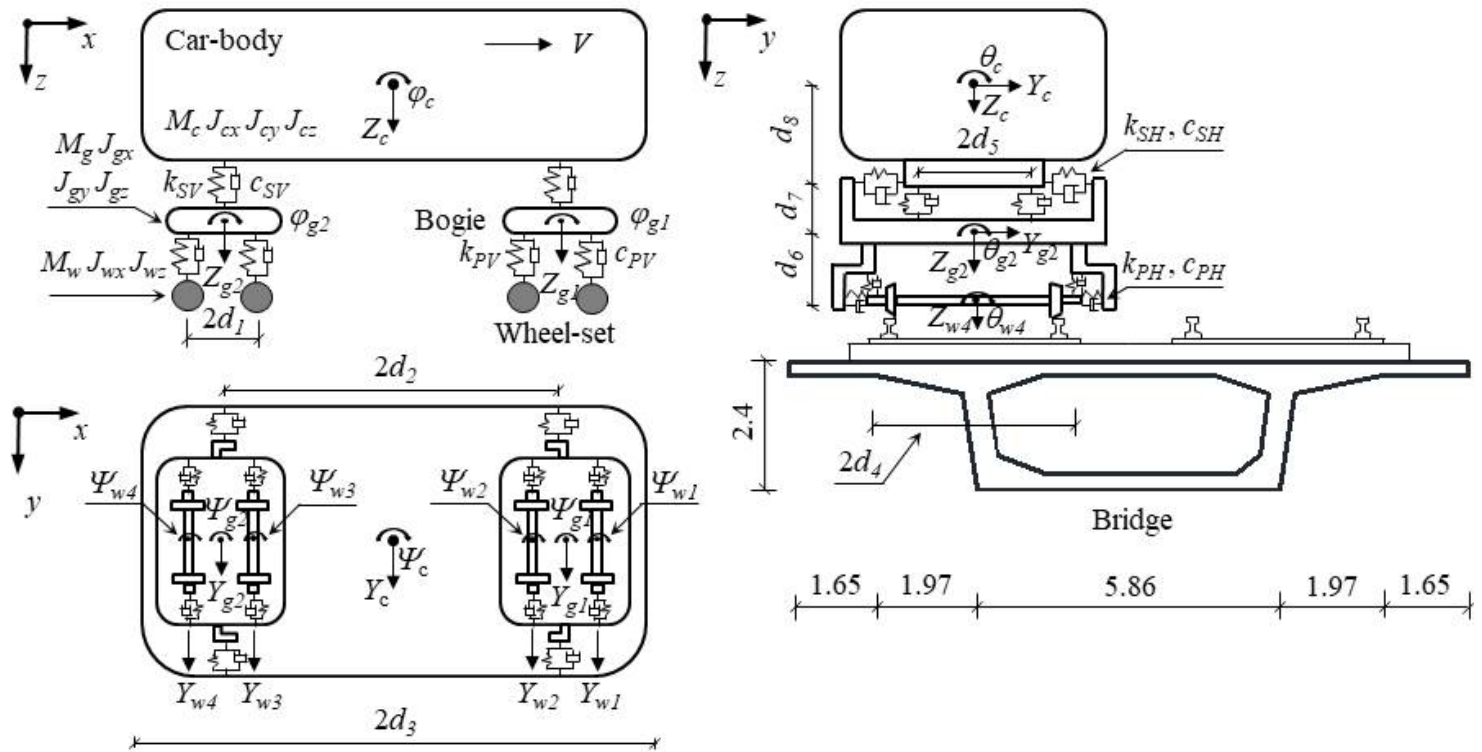

Figure 1 Four-axle high-speed train model (unit: $\mathrm{m}$ )

The train vehicle model shown in Fig. 1 represents a multiple DOFs and rigid-bodies dynamic system. If the following assumption is introduced: (a) train vehicles are independent of each other and (b) the elastic deformations of vehicles can be neglected, the motion of equation of train subsystem can be established by using the Lagrange's equation as

$\mathbf{M}_{v} \ddot{\mathbf{X}}_{v}+\mathbf{C}_{v} \dot{\mathbf{X}}_{v}+\mathbf{K}_{v} \mathbf{X}_{v}=\mathbf{F}_{v}$

where $\mathbf{M}_{v}$ is the vehicle mass matrix, in which the elements are the mass and inertia of moment associated with the abovementioned car-body, bogie, and wheel-set; $\mathbf{C}_{v}$ and $\mathbf{K}_{v}$ is the vehicle damping and stiffness matrices, in which the elements are associated with the characteristics of the primary and secondary suspension systems; $\mathbf{X}_{v}, \dot{\mathbf{X}}_{v}$, and $\ddot{\mathbf{X}}_{v}$ are, respectively, the displacement, velocity, and acceleration vectors which are built considering the DOFs of the car-body, bogie, and wheel-set described previously; and $\mathbf{F}_{v}$ is the vector of forces acting on the vehicle that will be deduced later on.

\subsection{Bridge model}

As shown in Fig. 1, a typical short-span simply-supported bridge adopted in high-speed railways is of box-shaped cross-section. The specific cross-section displayed in the figure represents the design proposal from one of high-speed rails in China. This box girder is $13.1 \mathrm{~m}$ wide and $2.4 \mathrm{~m}$ high, carrying double high-speed tracks. A numerical bridge model is developed with beam elements using the FE software ANSYS, in order to formulate the motion of equation of the bridge subsystem which can be written as

$\mathbf{M}_{b} \ddot{\mathbf{X}}_{b}+\mathbf{C}_{b} \dot{\mathbf{X}}_{b}+\mathbf{K}_{b} \mathbf{X}_{b}=\mathbf{F}_{b}$

where $\mathbf{M}_{b}, \mathbf{C}_{b}$, and $\mathbf{K}_{b}$ are the mass, damping, and stiffness matrices of the bridge, which can be established based on the bridge FE model; $\mathbf{X}_{b}, \dot{\mathbf{X}}_{b}$, and $\ddot{\mathbf{X}}_{b}$ are the displacement, velocity, and acceleration associated with the DOFs of the bridge structure; and $\mathbf{F}_{b}$ is the dynamic train loads applied on the bridge, which will be determined through the wheel-rail interaction model. In this study, a $23.1 \mathrm{~m}$-span simply-supported bridge commonly used in Chinese high-speed railway lines is investigated. Table 2 shows the main parameters of the bridge. Vertical, lateral, and torsional DOFs of the bridge are taken into account, which are sufficient to characterize the bridge movements. Accordingly, dynamic forces in the vertical, lateral, and torsional directions will act on the bridge by train vehicles. 
Table 2 Main parameters of the $23.1 \mathrm{~m}$ high-speed railway bridge.

\begin{tabular}{|c|c|c|}
\hline Parameter & Value & Unit \\
\hline Bridge span & 23.1 & $\mathrm{~m}$ \\
\hline Girder height & 2.4 & $\mathrm{~m}$ \\
\hline Bridge deck width & 13.1 & $\mathrm{~m}$ \\
\hline Girder cross-sectional area & 8.494 & $m^{2}$ \\
\hline Moment of inertia about the horizontal axis & 6.78 & $m^{4}$ \\
\hline Moment of inertia about the vertical axis & 80.296 & $\mathrm{~m}^{4}$ \\
\hline Concrete elasticity modulus & $3.45 \times 10^{4}$ & $\mathrm{MPa}$ \\
\hline Concrete density & 2500 & $\mathrm{~kg} / \mathrm{m}^{3}$ \\
\hline Secondary dead load & 16 & $\mathrm{t} / \mathrm{m}$ \\
\hline First bridge natural frequency & 7.75 & $\mathrm{~Hz}$ \\
\hline
\end{tabular}

\subsection{Wheel-rail interaction model}

The dynamic interactions between the high-speed train and bridge structure are related to the wheel-rail relationship. In general, these interactions can be classified into vertical and horizontal ones. In the vertical direction, it is assumed that the wheel-sets always contact with the rails. Hence, the vertical motion of each wheel-set equals that of the steel rail at its position. Specifically, the wheel-set motion is the superposition of the motion of box girder and vertical track irregularities. As shown in Fig. 2a, $F_{1}$ and $F_{2}$ represent the vertical forces produced in the primary suspension system, consisting of the linear spring and damping force components which can be obtained by multiplying the stiffness and damping parameters with the relative motion between the wheel-set and bogie. Accordingly, the expression of $F_{1}$ and $F_{2}$ can be written as

$$
\left\{\begin{array}{l}
F_{1}=k_{P V}\left[Z_{g}+\frac{d_{1}}{2} \eta \varphi_{g}-Z_{b}-Z_{t}+\frac{d_{4}}{2}\left(\theta_{b}+\theta_{t}-\theta_{g}\right)\right]+c_{P V}\left[\dot{Z}_{g}+\frac{d_{1}}{2} \eta \dot{\varphi}_{g}-\dot{Z}_{b}-\dot{Z}_{t}+\frac{d_{4}}{2}\left(\dot{\theta}_{b}+\dot{\theta}_{t}-\dot{\theta}_{g}\right)\right] \\
F_{2}=k_{P V}\left[Z_{g}+\frac{d_{1}}{2} \eta \varphi_{g}-Z_{b}-Z_{t}+\frac{d_{4}}{2}\left(\theta_{g}-\theta_{b}-\theta_{t}\right)\right]+c_{P V}\left[\dot{Z}_{g}+\frac{d_{1}}{2} \eta \dot{\varphi}_{g}-\dot{Z}_{b}-\dot{Z}_{t}+\frac{d_{4}}{2}\left(\dot{\theta}_{g}-\dot{\theta}_{b}-\dot{\theta}_{t}\right)\right]
\end{array}\right.
$$

where $k_{P V}$ and $c_{P V}$ are the vertical spring stiffness and damping of the primary suspension system; $Z_{b}$ and $\vartheta_{b}$ are the vertical and torsional motion of the girder associated with the track center; $Z_{t}$ and $\vartheta_{t}$ are the vertical and torsional track irregularities at the wheel-set location; $d_{1}$ and $d_{4}$ are the half distance between two wheel-sets and half span of the primary suspension system (see Fig. 1), respectively; and $\eta=1$ or -1 for the front or rear wheel-set corresponding to one bogie. In addition, force and moment balance equation is written with respected to each wheel-set (see Fig. 2a) to obtain the vertical force $F_{3}$ and $F_{4}$ at the wheel-rail contact location as

$$
\left\{\begin{array}{l}
F_{3}=\frac{1}{2} P+\left(\frac{1}{2}+\frac{d_{4}}{2 g_{0}}\right) F_{1}+\left(\frac{1}{2}-\frac{d_{4}}{2 g_{0}}\right) F_{2}+\frac{1}{2} M_{w}\left(\ddot{Z}_{b}+\ddot{Z}_{t}\right)-\frac{I_{w x}}{g_{0}}\left(\ddot{\theta}_{b}+\ddot{\theta}_{t}\right) \\
F_{4}=\frac{1}{2} P+\left(\frac{1}{2}-\frac{d_{4}}{2 g_{0}}\right) F_{1}+\left(\frac{1}{2}+\frac{d_{4}}{2 g_{0}}\right) F_{2}+\frac{1}{2} M_{w}\left(\ddot{Z}_{b}+\ddot{Z}_{t}\right)+\frac{I_{w x}}{g_{0}}\left(\ddot{\theta}_{b}+\ddot{\theta}_{t}\right)
\end{array}\right.
$$

where $P$ is the static axle load; $g_{0}$ is the track gauge; and $M_{w}$ and $I_{w x}$ are the mass and moment of inertia with respect to the $x$ axis of each wheel-set, respectively.
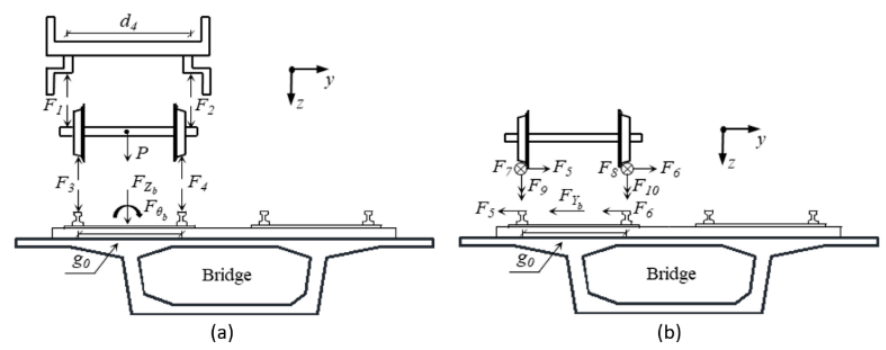

Figure 2 Wheel-rail interactions: (a) in the vertical direction; and (b) in the horizontal direction. 
In the horizontal direction, a linear wheel-rail interaction model based on the simplified Kalker creep theory reported in Zhang et al. (2010) is adopted herein. Main simplifications made in this linear model include: (a) normal wheel-rail contact forces generally fluctuating around the static axle load are considered as constant and equal to the static axle load; and (b) the coupling effects of the swaying DOF $Y_{w}$ and yawing DOF $\psi_{w}$ of the wheel-set are ignored. Adopting the Kalker creep theory and abovementioned assumptions, the horizontal wheel-rail forces, i.e., $F_{5}-F_{10}$ in Fig. 2b can be expressed as (Zhai et al. 1996; Zhang et al. 2010)

$$
\left\{\begin{array}{l}
F_{5 \text { or } 6}=-f_{11} \zeta_{1 L \text { or } I R}=\mp f_{11} g_{0} \dot{\psi}_{w} / 2 V \\
F_{7 \text { or } 8}=-f_{22} \zeta_{2 L \text { or } 2 R}=-f_{22}\left(\dot{Y}_{w}-\dot{Y}_{b}-\dot{Y}_{t L \text { or } t R}\right) / V \\
F_{9 \text { or } 10}=-f_{33} \zeta_{3 L \text { or } 3 R}=-f_{33} \dot{\psi}_{w} / V
\end{array}\right.
$$

where $f_{11}, f_{22}$, and $f_{33}$ are horizontal, longitudinal, and rotational creep coefficients which are the functions of the normal wheel-rail contact force, the wheel radius, and the radius of curvature at the wheel-rail contact point; $\zeta_{1}, \zeta_{2}$, and $\zeta_{3}$ are, respectively, the horizontal, longitudinal, and rotational creep ratios; $Y_{b}$ and $Y_{t}$ are the lateral displacement of the box girder and track irregularities; the subscripts $L$ and $R$ denote the left and right steel rails; and $V$ is the train speed.

Once the vertical and horizontal wheel-rail interactions are determined, forces on the train subsystem $\mathbf{F}_{v i}$ and bridge subsystem $\mathbf{F}_{b i}$ associated with the ith wheel-set can be obtained as

$\mathbf{F}_{v i}=\left\{\begin{array}{c}F_{\theta_{g}} \\ F_{Z_{g}} \\ F_{\varphi_{g}} \\ F_{Y_{w}} \\ F_{\psi_{w}}\end{array}\right\}=\left\{\begin{array}{c}d_{4}\left(F_{1}-F_{2}\right) / 2 \\ -\left(F_{1}+F_{2}\right) \\ -\eta d_{1}\left(F_{1}+F_{2}\right) / 2 \\ F_{5}+F_{6} \\ g_{0}\left(F_{7}-F_{8}\right) / 2+F_{9}+F_{10}\end{array}\right\}$

$\mathbf{F}_{b i}=\left\{\begin{array}{c}F_{Y_{b}} \\ F_{Z_{b}} \\ F_{\theta_{b}}\end{array}\right\}=\left\{\begin{array}{c}-\left(F_{5}+F_{6}\right) \\ F_{3}+F_{4} \\ g_{0}\left(F_{4}-F_{3}\right) / 2\end{array}\right\}$

It should be noted that since the wheel-set floating and rolling DOFs are determined by the motion of the girder and track irregularities and therefore non-independent, the corresponding forces are applied on the DOFs of the bogie as shown in Equation (6). Based on Equations (6) and (7), $\mathbf{F}_{v}$ and $\mathbf{F}_{b}$ on the right-hand sides of Equations (1) and (2) can be constructed. Subsequently, the equation of motion of the train-bridge system can be obtained by grouping Equations (1) and (2) as

$\left\{\begin{array}{l}\mathbf{M}_{v} \ddot{\mathbf{X}}_{v}+\mathbf{C}_{v} \dot{\mathbf{X}}_{v}+\mathbf{K}_{v} \mathbf{X}_{v}=\mathbf{F}_{v} \\ \mathbf{M}_{b} \ddot{\mathbf{X}}_{b}+\mathbf{C}_{b} \dot{\mathbf{X}}_{b}+\mathbf{K}_{b} \mathbf{X}_{b}=\mathbf{F}_{b}\end{array}\right.$

\subsection{Solution scheme of the system equation}

A numerical solution scheme is formulated in this study to solve Equation (8), which consists of the following iterative steps:

(1) Solve the vehicle equation of motion through an in-house program developed in MATLAB using the Newmark- 6 method (Newmark 1959). In this step it is assumed that no motion is present on the bridge including steel rails. Hence, track irregularities serve as the cause of vehicle vibrations.

(2) Solve the bridge equation of motion to obtain the bridge dynamic responses by performing the transient analysis with the bridge FE model established and the computing procedure developed in ANSYS. In this step the dynamic forces applied on the bridge (i.e., Equation (7)) are calculated based on the results from the previous iterative loop or the first step. 
(3) Solve the vehicle equation of motion with the obtained data of bridge motion in the second step and numerical samples of track irregularities, in order to acquire the updated forces acting on the bridge subsystem.

(4) Compare time histories of the bridge forces obtained from the third step and the previous iterative loop (or the first step) and calculate the differences between the two data sets.

Once the absolute differences associated with the lateral, vertical, and torsional forces produced by each wheel-set at any point in time fall within the allowable range (e.g., less than $1 \%$ of the force itself), the abovementioned iterative procedure stops and the bridge displacements can be obtained and displayed in ANSYS post-processing module.

Fig. 3 shows the raw displacement time-histories of the bridge mid-span computed in four consecutive runs of the ANSYS transient analysis module without data filtering. In this illustrative case, the running speed of the high-speed train with eight vehicles is $300 \mathrm{~km} / \mathrm{h}$. The German low-interference track spectrum for high-speed rails is employed to generate the numerical samples of the lateral, vertical, and torsional track irregularities (Zhai and Xia 2011). Additionally, the damping ratio of the bridge is considered as $2 \%$. Combining this value with the fundamental vertical and lateral vibration frequencies $\left(7.75 \mathrm{~Hz}\right.$ and $24.78 \mathrm{~Hz}$ respectively) of the bridge, the damping matrix $\mathbf{C}_{b}$ in Equation (2) can be calculated based on the Rayleigh damping expression (Clough and Penzien 2003). It can be seen in Fig. 3 that after three runs in ANSYS, the vertical displacement responses of the bridge mid-span become stable. The displacement time-histories of run 2 and 3 are quite close to each other, and results from run 4 are nearly the same with those of run 3 . Consequently, the displacement obtained at the third run can be considered final and used to perform the safety evaluation of the highspeed train and bridge system.

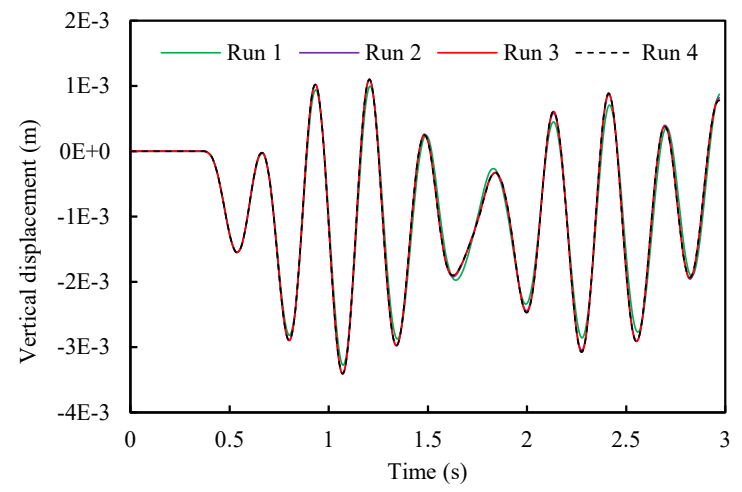

Figure 3 Vertical displacement time-histories of the bridge mid-span due to high-speed train loads.

\section{Methodology based on ML}

\subsection{ANN}

ANNs are virtually a kind of mathematical algorithms created with the inspirations from biology (Fausett 1994). In the biology neural system, information received is processed in the neural system composed of neurons. Similarly, a single neuron can be mathematically developed as shown in Fig. 4. For an input vector $\mathbf{x}$ consisting of $x_{1}$ to $x_{n}$, the temporary value $z$ can be yielded after a weighted summation operation as

$$
z=\sum_{i=1}^{n} w_{i} x_{i}+b=\mathbf{w} \mathbf{x}+b
$$

where $w_{i}$ is the weight associated with the ith input and it forms a weight vector $\mathbf{w}$; and $b$ is the bias assigned to the neuron. Subsequently, a nonlinear activation function is applied on the sum $z$ to improve the fitting ability of the neuron. For instance, the activation operation can be achieved using the tanh-function to obtain the output $y$ as

$$
y=f(z)=\frac{e^{z}-e^{-z}}{e^{z}+e^{-z}}
$$




\section{INPUT WEIGHT SUMMATION ACTIVATION OUTPUT}

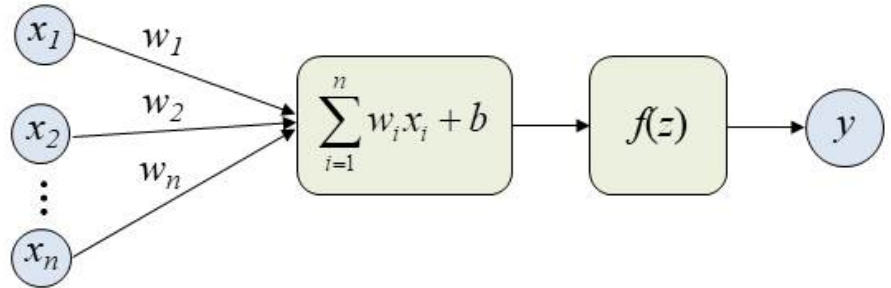

Figure 4 The model of a single neuron.

The neural networks composed of multiple layers of neurons can handle complex mapping problems in dynamic structural systems. Usually one input layer, several hidden layers, and one output layer can be found in the neural network. In this study, the input layer denotes variables associated with the high-speed train and bridge structure. The hidden layer is made up of several neurons with respective weights and bias. Additionally, the output layer represents the maximum displacement of the bridge mid-span produced by the passing high-speed train. Fig. 5 shows the model of a neural network with multiple hidden layers. In the neural network, each node of the hidden layer (i.e., neuron) or output layer is entirely connected with all the nodes in the former layer. The temporary value $z_{j}^{(l+1)}$ of the jth neuron in the $(/+1)$ th hidden layer is calculated using the weighted sum of all the outputs associated with the neurons in the /th hidden layer as

$z_{j}^{(l+1)}=\sum_{i=1}^{n} w_{j i}^{(l)} x_{i}^{(l)}+b_{j}^{(l+1)}=\mathbf{w}^{(l)} \mathbf{x}^{(l)}+b_{j}^{(l+1)}$

where $\mathbf{x}^{(l)}$ is the output vector of the /th hidden layer; $b_{j}^{(l+1)}$ is the bias assigned to the $j$ th neuron in the $(/+1)$ th hidden layer; and $\mathbf{w}^{(l)}$ is the weight matrix that can be expressed as

$\mathbf{w}^{(l)}=\left[\begin{array}{cccc}w_{11}^{(l)} & w_{12}^{(l)} & \cdots & w_{l n}^{(l)} \\ w_{2 l}^{(l)} & w_{22}^{(l)} & \cdots & w_{2 n}^{(l)} \\ \vdots & \vdots & & \vdots \\ w_{m l}^{(l)} & w_{m 2}^{(l)} & \cdots & w_{m n}^{(l)}\end{array}\right]$

where $m$ is the number of neurons in the /th hidden layer. It can be seen from Equation (11) and Fig. 5 that the value of $z_{j}^{(l+1)}$ depends on $w_{j i}^{(l)}$ and $x_{i}^{(l)}$ of the previous layer. Hence, a forward propagation from left to right as shown in Fig. 5 is present in ANNs. The output $y$ resulting from the ANNs is compared with the expected output values. Adjusting values of the weight and bias through optimization algorithms to reduce the errors between the predicted and expected output values constitutes the back propagation training process of ANNs.

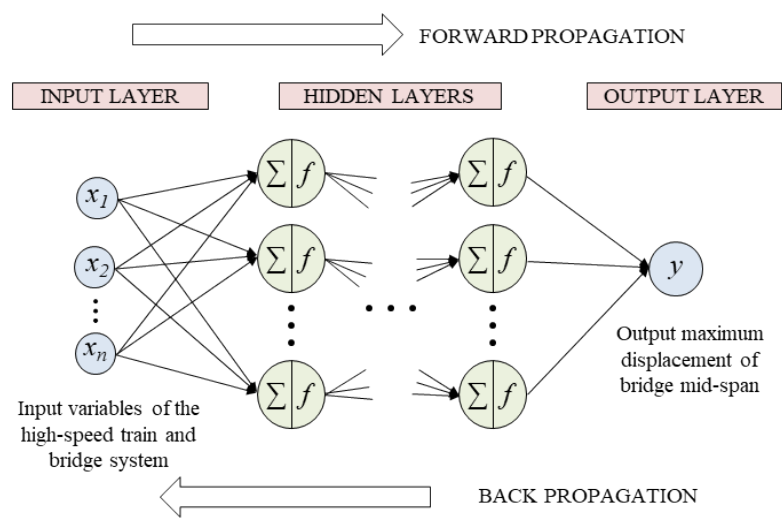

Figure 5 The multilayer neural network configuration. 
In the present analysis MATLAB is employed to build and train the neural networks. During the training process, the following elements are emphasized.

(1) Values of the input variables which are selected from either high-speed train or bridge (including track) parameters demonstrate large differences in terms of order of magnitude. Therefore, the inputs are normalized to be within $[-1,1]$ before they go into the first hidden layer. Accordingly, a denormalization operation should be conducted with respect to the raw output data to obtain the real bridge displacement resulting from ANNs.

(2) The Levenberg-Marquardt algorithm (Marquardt 1963) and Bayesian regulation algorithm (David 1992) are adopted to train the neural network. The algorithms can address multidimensional nonlinear regression without constraints based on least squares. ANN model parameters (e.g., weight and bias) are rapidly found minimizing the error function one type of which can be expressed as

$$
\text { ERROR }=\frac{1}{2} \sum_{h=1}^{g}\left(y_{h}^{\text {target }}-y_{h}^{\text {output }}\right)^{2}
$$

where $y_{h}^{\text {target }}$ and $y_{h}^{\text {output }}$ are the $h$ th expected and predicted output value respectively; and $g$ is the output dimension which equals one in this study. Additionally, the performance of the ANN established is evaluated by calculating the mean squared error (MSE) defined as the expectation of squared differences between the predicted and true values. The training process is regarded as completed once the MSE reaches a stable and sufficiently small value.

(3) The number of layers and neurons in the hidden layers has a significant impact on the performance of the ANN. Generally, increasing the number of hidden layers makes the neural network more accurate but also more complicated which leads to the increase in training time. A neural network composed of one input layer, one hidden layer, and one output layer becomes the preferred choice in designing the network architecture. In addition, influential factors associated with the determination of neuron numbers in the hidden layers include the complexity of the problem to be solved, type of the activation function, characteristics of the training data, neuron number of the input and output layers, and so on. There is no universal determination method at present (Benardos and Vosniakos 2007). One practical principle suggests that the neurons should be as few as possible if the accuracy requirements are satisfied. In this study, 10 neurons are arranged in the hidden layer.

(4) The activation function classified into the linear and nonlinear also has impact on the performance of the neural network. Considering the nonlinearity of the mapping problem investigated in the present analysis, the nonlinear tanh-function shown in Equation (10) is utilized for the hidden layer and the linear purelin-function for the output layer as

$y=f(z)=z$

\subsection{Input and output variables}

As discussed previously, since track irregularities as well as properties related to the vehicle and bridge structure cause random vibrations, it is widely recognized that a coupling train-bridge dynamic analysis as demonstrated in section 2.4 yields only one sample of the output. In order to produce sufficient training samples for the ANN built previously, Monte-Carlo simulation based on the numerical model of the train-bridge system is implemented herein.

Track irregularities which show a stationary ergodic random process have been considered as the most important excitation within the train-bridge system (Zhai et al. 2019; Li et al. 2017). Therefore, probabilistic vibration analyses have been conducted treating the irregularity as the sole random variable (Yu et al. 2016; Jin et al. 2015; Han et al. 2019). In the present analysis each run of the Monte-Carlo simulation employs one sample of track irregularities generated from the power spectrum of the German low-interference track. In the existing research, Cho et al. (2010) selected the bridge damping ratio, concrete elasticity modulus, and cross-sectional area as the random parameters for the calculation of bridge dynamic deflection. Rocha et al. (2012) performed a variable sensitivity analysis without considering track irregularity to find out which one has impact on the bridge dynamic responses. It was reported in their study that concrete elasticity modulus, cross-section height, and ballast area can be sensitive variables for bridge displacement. Since the $23.1 \mathrm{~m}$ bridge under investigation is non-ballasted and unified forms are used during the factory manufacturing of the concrete girder, the randomness corresponding to the ballast area and cross-section height is neglected. 
In this study, track irregularities, concrete elasticity modulus, structural damping ratio, car-body mass, and train speed are chosen as the random parameters in the high-speed train and short-span bridge system. The variation of carbody mass due to the different numbers of passengers on board can affect the vehicle weight and therefore the forces between the train and bridge. In addition, train speed has significant impact on the dynamic responses of the bridge (Liu et al. 2009; Xia et al. 2014; Ribes-Llario et al. 2016). Detailed information including the distribution, mean, and standard deviation of these parameters is demonstrated in Table 3. The car-body mass follows the uniform distribution and its minimum and maximum values are associated with the empty and full vehicle respectively. Accordingly, the random variables shown in Table 3 are also appointed as the input variables of the BP-ANN. It should be noted that the track irregularity is represented by its mean and standard deviation calculated based on each sample data in the vertical, lateral, and torsional directions. Therefore, there are 10 input features in total. The output variable is determined as the maximum displacement at bridge mid-span, since the peak responses usually govern the structural safety.

Table 3 Random variables considered in the high-speed train and bridge system.

\begin{tabular}{cccc}
\hline Variable & Distribution type & $\begin{array}{c}\text { Mean (normal) or } \\
\text { minimum (uniform) }\end{array}$ & $\begin{array}{c}\text { Std. Deviation (normal) } \\
\text { or maximum (uniform) }\end{array}$ \\
\hline Track irregularity & - & - & - \\
Reference & Zhai and Xia (2011) \\
Concrete elasticity modulus & Normal & $3.45 \times 10^{4} \mathrm{MPa}$ & $2.76 \times 10^{3} \mathrm{MPa}$ \\
Bridge damping ratio & Normal & $2 \%$ & $0.3 \%$ \\
Car-body mass & Uniform & $4 \times 10^{4} \mathrm{~kg}$ & $4.8 \times 10^{4} \mathrm{~kg}$ \\
Train speed & Normal & $300 \mathrm{~km} / \mathrm{h}$ & $5 \mathrm{~km} / \mathrm{h}$ \\
\hline
\end{tabular}

\subsection{Computational framework}

Fig. 6 shows the computational framework of the ML based approach proposed in this study, which consists of three modules. In the Monte-Carlo simulation module, samples of the variables reported in Table 3 are randomly produced according to their distribution information. Coupling dynamic analysis using the complete high-speed train and bridge system model in section 2 is conducted based on each set of the random and deterministic parameters. The BP-ANN training module takes the mean value and standard deviation of track irregularities, concrete elasticity modulus, bridge damping ratio, car-body mass, and train speed as the input of the neural network. Additionally, maximum displacements of the bridge mid-span resulting from the Monte-Carlo simulation serve as the network output. Subsequently, a 10-10-1 architecture network is trained with the obtained input and output data in MATLAB platform.

It should be noted that the input and architecture of the BP-ANN is subjected to adjustment aiming at the establishment of an efficient and accurate network. The optimized network is adopted to predict the displacement response produced by the high-speed train with new input data. Based on the prediction, evaluation of the high-speed train and bridge system is finally carried out.

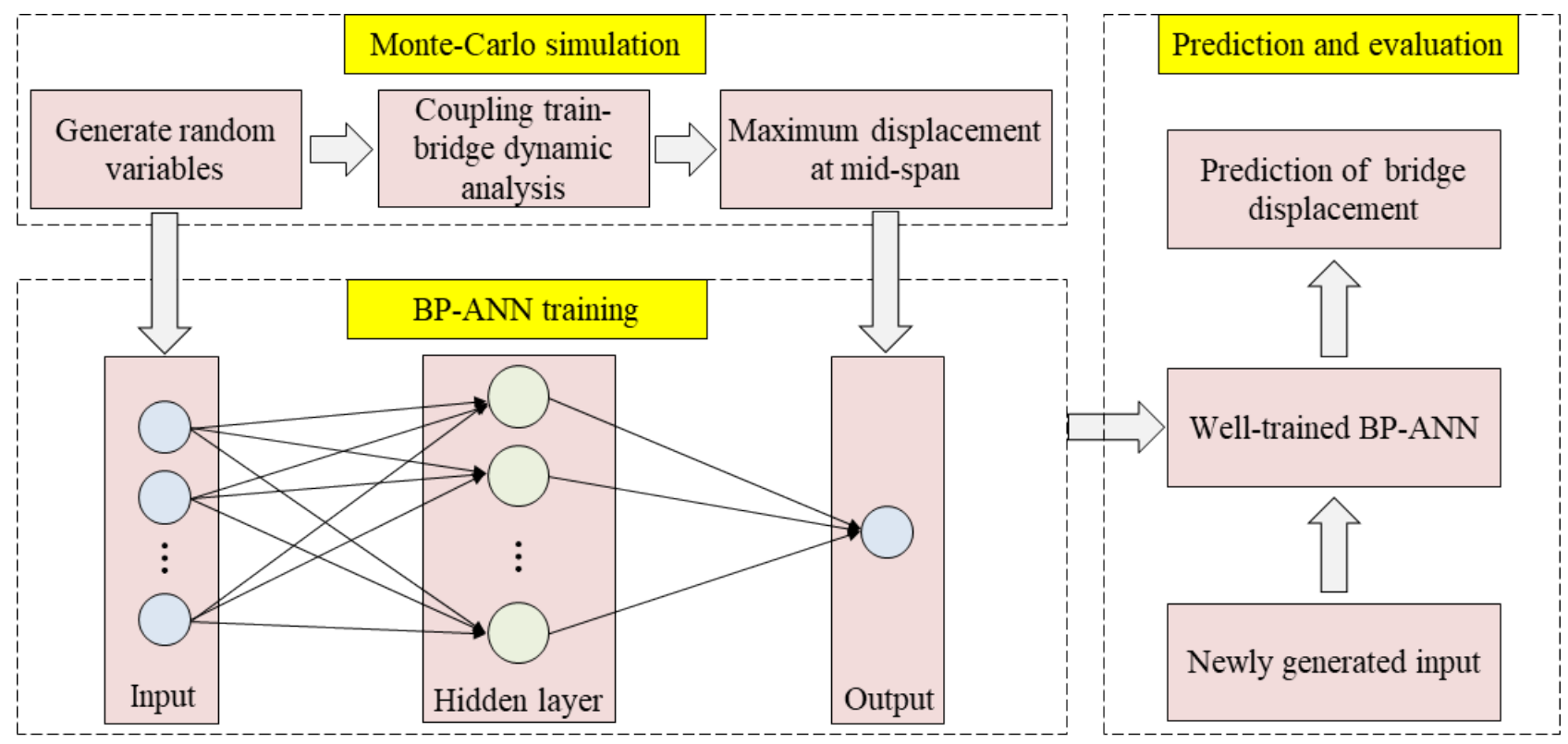

Figure 6 Framework of the proposed methodology. 


\section{Prediction and evaluation}

\subsection{Comparison and selection of neural networks}

In order to identify the networks that can map the dynamic high-speed train and bridge system, extensive investigation is herein performed on various network architectures as shown in Table 4 . The input features of the network vary with the change in the determination of input variables. Initially, ten input nodes as discussed previously is selected in networks 1-1 and 1-2 corresponding to statistical characteristics of the track irregularities in time domain, concrete elasticity modulus, bridge damping ratio, car-body mass, and train speed. Furthermore, four and three variables are respectively considered in the input layers of networks 2-1, 2-2, 3-1 and 3-2, and accordingly, three network architectures are examined. In addition, each type of network architecture adopts both the Levenberg-Marquardt and Bayesian regulation algorithms for the training process. In total there are six different networks to be optimized.

Table 4 Neural networks considered in the present analysis.

\begin{tabular}{ccccc}
\hline Name & $\begin{array}{c}\text { Network } \\
\text { architecture }\end{array}$ & $\begin{array}{c}\text { Number of } \\
\text { Input variable }\end{array}$ & Input variable & Training algorithm \\
\hline $\begin{array}{c}\text { Network 1-1 } \\
\text { Network 1-2 }\end{array}$ & $10-10-1$ & 10 & $\begin{array}{c}\text { Mean and Std. deviation of track } \\
\text { irregularities, concrete elasticity } \\
\text { modulus, bridge damping ratio, car- } \\
\text { body mass, train speed }\end{array}$ & $\begin{array}{c}\text { Levenberg-Marquardt } \\
\text { Bayesian regulation }\end{array}$ \\
$\begin{array}{c}\text { Network 2-1 } \\
\text { Network 2-2 }\end{array}$ & $4-10-1$ & 4 & $\begin{array}{c}\text { Concrete elasticity modulus, bridge } \\
\text { damping ratio, car-body mass, train } \\
\text { speed }\end{array}$ & $\begin{array}{c}\text { Levenberg-Marquardt } \\
\text { Bayesian regulation }\end{array}$ \\
$\begin{array}{c}\text { Network 3-1 } \\
\text { Network 3-2 }\end{array}$ & $3-10-1$ & 3 & Concrete elasticity modulus, bridge \\
damping ratio, train speed & $\begin{array}{c}\text { Levenberg-Marquardt } \\
\text { Bayesian regulation }\end{array}$ \\
\hline
\end{tabular}

The amount of training data has significant impact on the performance of neural networks. In the present analysis, all the six considered neural networks are optimized using up to 2000 data sets. At each training data volume, ten training processes are completed with randomly generated data sets. Then, the average of the MSE produced from the ten training processes is estimated, as shown in Fig. 7. The smaller MSE becomes, the better the network performance will likely be. One can observe from the figure that the realization of stable and small MSE values requires sample data sets larger than 1000. Nevertheless, greater value and variation can be found in MSE of networks trained with LevenbergMarquardt algorithm than that using Bayesian regulation algorithm. Consequently, the Bayesian regulation algorithm and corresponding networks 1-2, 2-2, and 3-2 are determined for the following prediction of dynamic bridge displacements. This choice can also be justified by the regression coefficient $R$ results associated with training and test as shown in Fig. 8. Herein $R$ is an important measure of the network performance in addition to the abovementioned MSE. The close $R$ is to 1 , the better linear relationship between the output values of the network and sample data can be obtained.

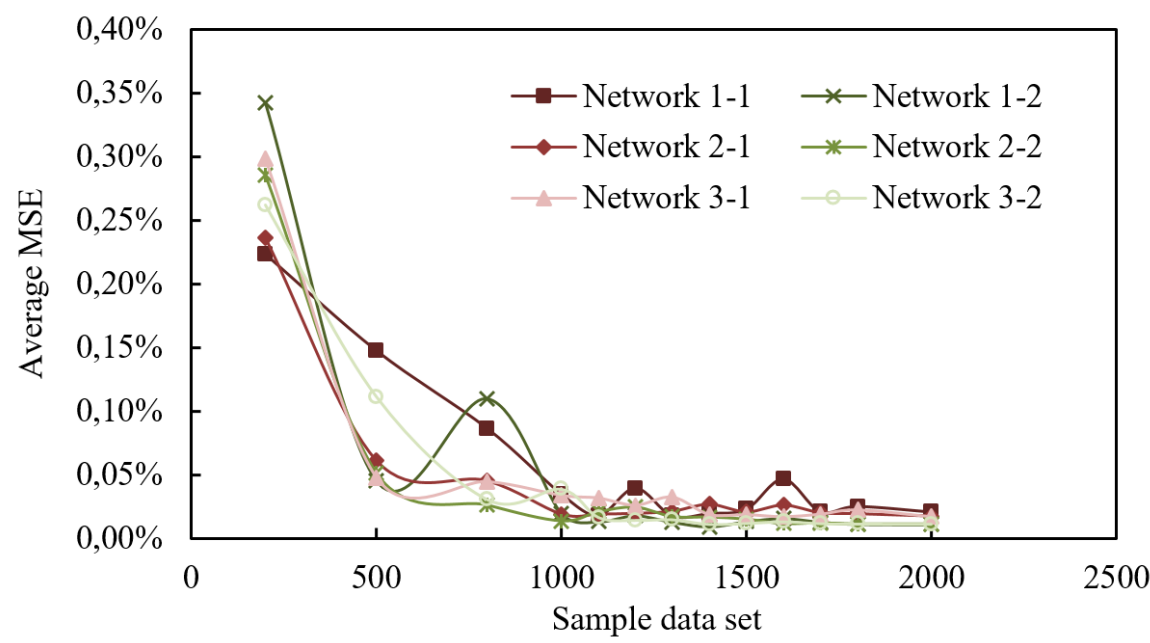

Figure 7 MSE obtained from considered neural networks and data set volumes. 


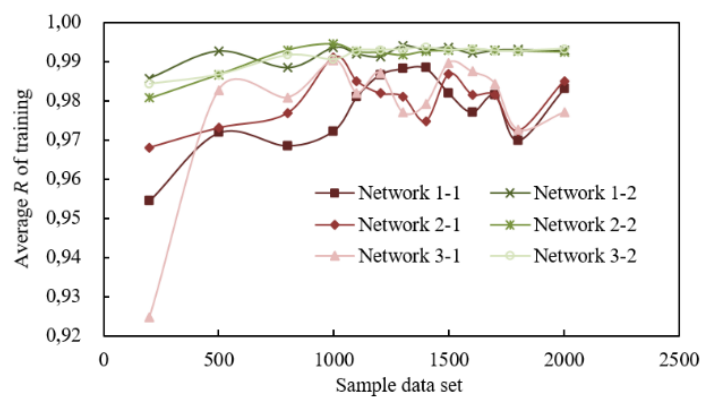

(a)|

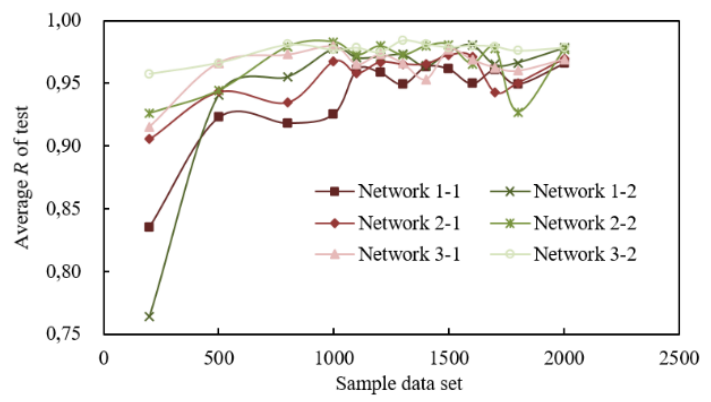

(b)

Figure 8 Average of the regression coefficient $\mathrm{R}$ of $(\mathrm{a})$ the training and (b) the test for considered neural networks and data set volumes.

The standout of networks 2-2 and 3-2 leads to a significant finding that concrete elasticity modulus, bridge damping ratio, car-body mass, and train speed are sufficient to construct an efficient BP-ANN for dynamic displacement prediction of the random high-speed train and bridge system. In other words, the random variation in track irregularities has relatively low-impact on the maximum displacement of the bridge compared to other parameters although it is believed that the displacement time histories can be largely affected by the irregularities. The concrete elasticity modulus and bridge damping ratio can be obtained in the bridge routine inspection campaign and field test, and usually remain steady during the time interval of two inspections. Accurate train speed can be easily acquired using mature technology. In spite of the fact that the preparation of over 1000 training data sets takes several days in this study as the train-bridge dynamic simulation is performed in a single PC computer with Intel Core i7 CPU at $3.4 \mathrm{GHz}$, this simulation can be completed beforehand as well as the training process of the network. Therefore, the proposed methodology herein can pave the way for online evaluation of the high-speed train and bridge system using network 3-2 since the prediction employing the well-trained network takes only milliseconds as discussed later on.

It should be noted that although the MSE and $R$ of networks 1-2, 2-2, and 3-2 are generally similar if the data is over 1000 , the most favorable values of MSE or $R$ exist at different amount of data set. After careful and comprehensive comparison, network 1-2 with 1100 training data, network 2-2 with 1000 training data, and network 3-2 with 1400 training data are considered. In particular, networks demonstrating the best performance among the ten repetitions of training are eventually selected for the following prediction and evaluation. For illustration purposes, training performance results of the selected network 3-2 are displayed in Fig. 9 and Fig. 10.

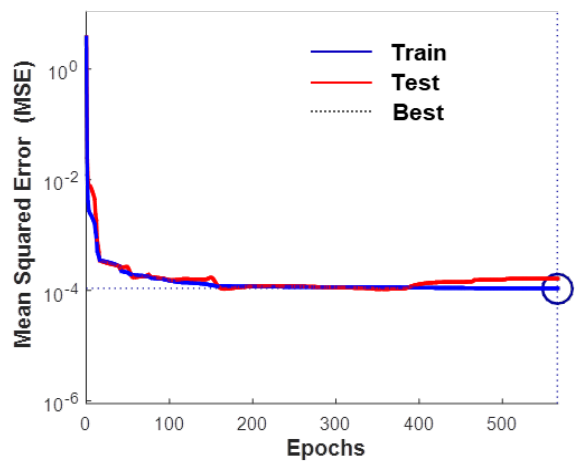

Figure 9 Training and test MSE obtained from the selected network 3-2. 


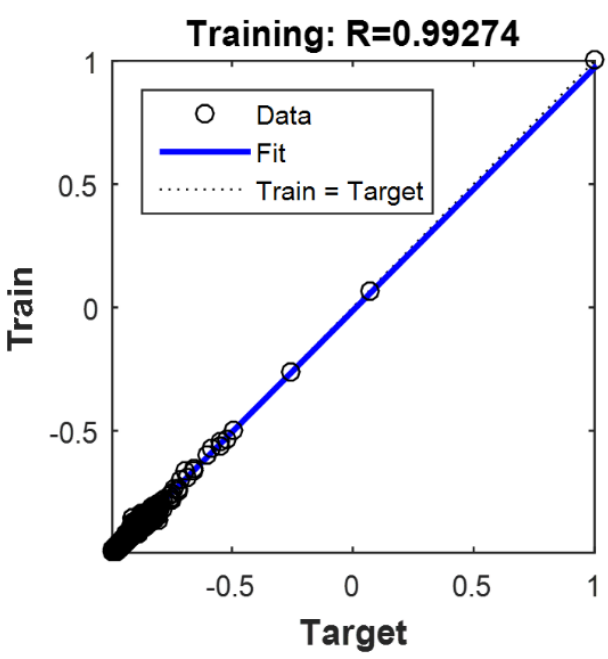

(a)

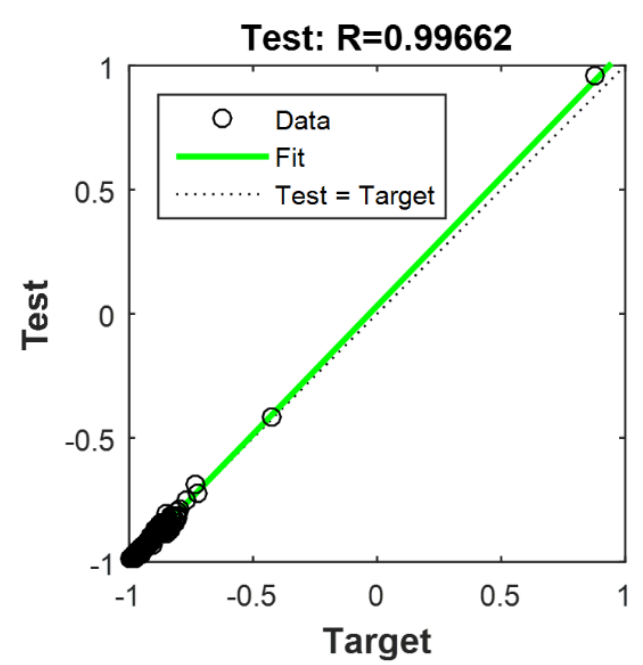

(b)

Figure 10 Regression analysis: (a) training and (b) test results from the selected network 3-2.

\subsection{Predicted results}

The merit of the proposed approach is the realisation of efficient bridge displacement prediction using the welltrained ANNs. To this end, the networks discussed previously are adopted to produce the train-induced displacement response based on the inputs without conducting the complicated and time-consuming numerical analysis. Specifically, three groups of 100 brand-new input data sets are generated based on the probability model listed in Table 3, corresponding to the three selected networks trained in section 4.1. Theses inputs are applied to the ANNs respectively and the associated 100 predicted maximum displacement values of the bridge mid-span due to the passing of high-speed train are acquired, as shown in Fig. 11. In the figure, the true values denote the displacements computed through the coupling dynamic analysis of high-speed train and bridge system. It can be seen that all the three selected networks are able to give satisfactory predictive results. In particular, the network 3-2 has superior performance in the cases of larger displacement response. This observation confirms that network 3-2 with only three input features, namely, concrete elasticity modulus, bridge damping ratio, and train speed, can provide reliable predictions.

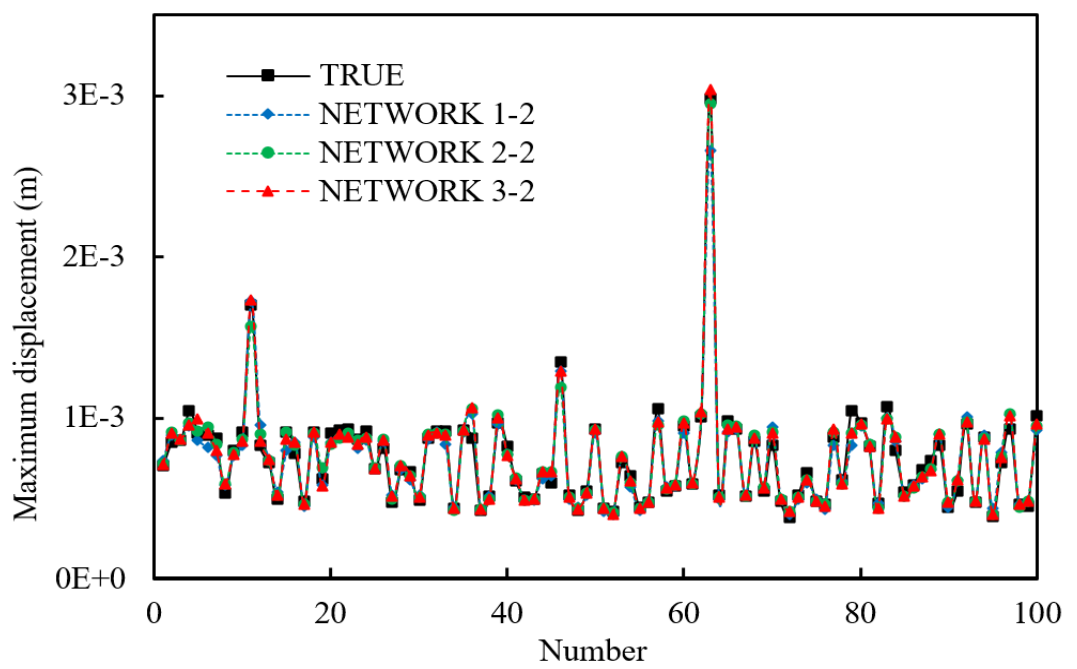

Figure 11 Prediction results of the maximum displacement at bridge mid-span using the three selected networks.

Fig. 12 shows the predictive error (the ratio of difference between the prediction and true value to the true value) corresponding to Fig. 11. We can see that most of errors are under $10 \%$ which can be considered as satisfactory. For network 3-2 and 2-2, there are three and four out of 100 errors exceeding $10 \%$, which merely constitutes $3 \%$ and $4 \%$ of the total predictions, respectively. The average errors associated with networks 1-2, 2-2, and 3-2 can be calculated as 
$5.1 \%, 4.25 \%$, and $4.06 \%$. In these prediction cases, it can be seen that networks 3-2 and 2-2 with fewer input features can even outperform the network 1-2 with all the initial ten input features.

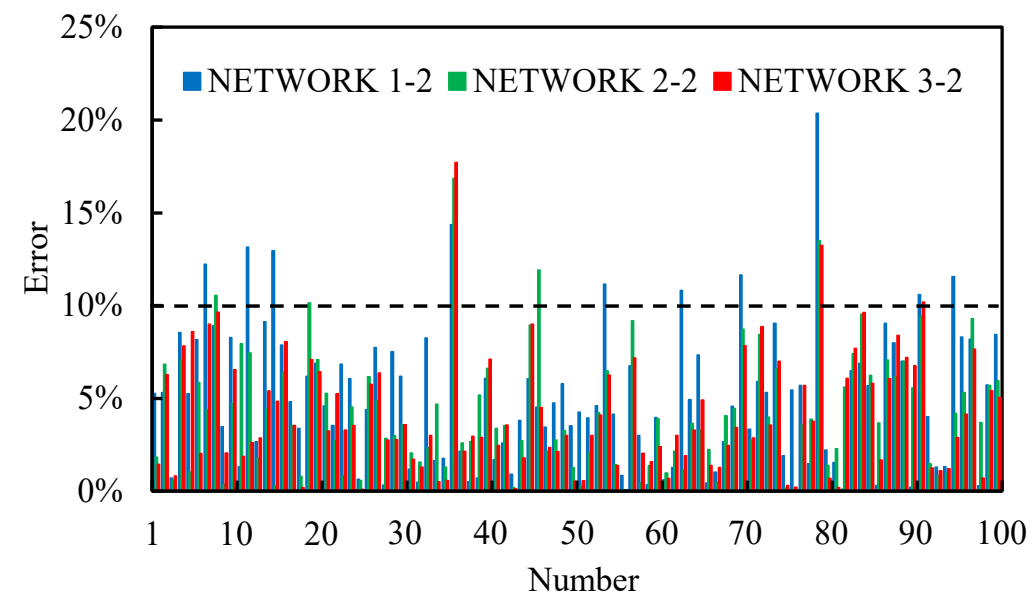

Figure 12 Prediction errors of the maximum displacement at bridge mid-span corresponding to networks 1-2, 2-2, and 3-2.

\subsection{Safety evaluation}

The satisfactory performance of network 3-2 allows the prediction and evaluation of train-induced bridge response in a probabilistic manner. First, $10^{6}$ random input samples of concrete elasticity modulus, bridge damping ratio, and train speed are generated in MATLAB. These random parameters are subsequently input to the network 3-2 to produce $10^{6}$ outputs, i.e., maximum bridge mid-span displacement. The simulation process using ANN is completed within one second. While conducting the train-bridge coupling dynamic analysis $10^{6}$ times is simply unrealistic using the same computing power. According to Codes for Design of High Speed Railway (National Railway Administration 2014), the vertical deformation limit is defined as the ratio of deflection to bridge span. For the bridges shorter than $40 \mathrm{~m}$, this limit is prescribed as $1 / 1600$. Therefore, the allowed maximum vertical displacement associated with the bridge considered is calculated as $14.4 \mathrm{~mm}$. Among the $10^{6}$ predicted displacement results no exceedance is observed. Accordingly, probability of exceedance will be smaller than $10^{-6}$. Consequently, from the perspective of critical displacement, the highspeed train and bridge system analyzed in this study is quite safe.

In addition, the well-trained network 3-2 can enables the online evaluation since the prediction process is instantaneous. For a high-speed railway line, the types and operating speed of running trains are usually fixed. Taking this advantage, a tailored BP-ANN similar to network 3-2 can be prepared for a specific train-bridge system. The preparation of training data using numerical train-bridge model established in section 2 can take a few days. Nevertheless, the training process of the network is very fast (in tens of seconds) and once it is completed the welltrained network will need no change during its application for quite a long period of time.

\section{Conclusions}

In this study, an approach for efficient prediction of bridge dynamic displacements and safety condition of the highspeed train and short span bridge system is presented using BP neural networks. The proposed approach consists of a complete train-bridge system analysis model which is developed to capture the real dynamic responses of the bridge due to high-speed trains. A numerical iteration procedure combining and utilizing commercial software ANSYS and MATLAB are designed to solve the dynamic equation of the system model in an effective manner. Selected parameters representing main random features in the train-bridge system and maximum bridge displacement obtained from the numerical analysis serve as the input and output data for the established BP neural networks. Various network architectures are investigated to compare their performance and to identify the optimal network. In addition, the proposed approach is illustrated using the actual engineering background from a typical high-speed railway system in China. The following conclusions can be drawn from the study:

(1) BP-ANN is an effective tool to the acquiring of dynamic displacement response of bridges due to coupling highspeed train loads, in addition to the conventional field measurement and numerical analysis. Over 1000 training samples are required to train the three-layer neural networks established in the present analysis for satisfactory performance. 
(2) Bayesian regulation algorithm yields better performance for all the network architectures investigated than the Levenberg-Marquardt algorithm. Average prediction errors for the three selected networks are basically smaller than 5\%. In particular, network 3-2 with the input of concrete elasticity modulus, bridge damping ratio, and train speed has comparable and even better predictive ability than those with more input features.

(3) The established networks can be prepared using the presented methodology in advance and applied for prediction and evaluation without extra efforts during a specific period of time (e.g., time interval between two bridge inspections). Furthermore, network 3-2 with a 3-10-1 architecture has considerable potentials in allowing online prediction and evaluation of the train and bridge system.

(4) The proposed approach also permits the probabilistic dynamic analysis of the train and bridge system. According to the design code, the probability of exceedance related to the bridge displacement is smaller than $10^{-6}$ in the present analysis, based on the massive simulation within seconds enabled by the well-trained neural network.

\section{Acknowledgements}

The authors gratefully acknowledge financial support from the National Natural Science Foundation of China (Grant Nos. 51708112 and 51525801$)$.

Author's Contributions: Conceptualization, HL Li and G Wu; Methodology, HL Li and G Wu; Investigation, HL Li, G Wu and MD Cui; Writing - original draft, HL Li, G Wu and MD Cui; Writing - review \& editing, HL Li, G Wu and MD Cui; Funding acquisition, G Wu and HL Li; Resources, G Wu; Supervision, G Wu.

Editor: Marcílio Alves.

\section{References}

ANSYS Inc. (2014) ANSYS user manuals version 15.1. Canonsburg, PA: ANSYS Inc., Global Headquarters.

Antolín, P., Zhang, N., Goicolea, J.M., Xia, H., Astiz, M.A., Oliva, J. (2013) Consideration of nonlinear wheel-rail contact forces for dynamic vehicle-bridge interaction in high-speed railways, Journal of Sound and Vibration 332: 1231-51.

Benardos, P.G., Vosniakos, P.G. (2007) Optimizing feedforward artificial neural network architecture, Engineering Applications of Artificial Intelligence 20(3): 365-382.

Cho, T.J., Song, M.K., Lee, D.H. (2010) Reliability analysis for the uncertainties in vehicle and high-speed railway bridge system based on an improved response surface method for nonlinear limit states, Nonlinear Dynamics 59: 1-17.

Clough, R.W., Penzien, J. (2003) Dynamics of structures, McGraw Hill.

David, J.C. (1992) A practical Bayesian framework for backprop networks, Neural Computation 4(3): 448-472.

Deng, Y., Zhang, M., Feng, D.M., Li, A.Q. (2020) Predicting fatigue damage of highway suspension bridge hangers using weigh in-motion data and machine learning, Structure and Infrastructure Engineering, DOI: 10.1080/15732479.2020.1734632.

Fausett, L.V. (1994) Fundamentals of neural networks: architectures, algorithms, and applications. Englewood Cliffs: PrenticeHall.

Feng, D.M., Feng, M.Q. (2018) Computer vision for SHM of civil infrastructure: From dynamic response measurement to damage detection-A review, Engineering Structures 156: 105-117.

Galvín, P., Romero, A., Moliner, E., Martínez-Rodrigo, M.D. (2018) Two FE models to analyse the dynamic response of short span simply-supported oblique high-speed railway bridges: comparison and experimental validation, Engineering Structures 167: 48-64.

Gou, H.Y., Yang, L.C., Mo, Z.X. (2019) Effect of long-term bridge deformations on safe operation of high-speed railway and vibration of vehicle-bridge coupled system, International Journal of Structural Stability and Dynamics 19(9): 1950111-1-33.

Han, X., Xiang, H.Y., Li, Y.L., Wang, Y.C. (2019) Predictions of vertical train-bridge response using artificial neural networkbased surrogate model, Advances in Structural Engineering 22(12): 2712-2723. 
Jin, Z.B., Pei, S.L., Li, X.Z., Qiang, S.Z. (2015) Probabilistic evaluation approach for nonlinear vehicle-bridge dynamic performances, Journal of Sound and Vibration 339: 143-156.

Li, H.L., Frangopol, D.M., Soliman, M., Xia, H. (2016) Fatigue reliability assessment of railway bridges based on probabilistic dynamic analysis of a coupled train-bridge system, Journal of Structural Engineering 142(3): 04015158-1-16.

Li, H.L., Soliman, M., Frangopol, D.M., Xia, H. (2017) Fatigue Damage in Railway Steel Bridges: Approach Based on a Dynamic Train-Bridge Coupled Model, Journal of Bridge Engineering 22(11): 06017006-1-8.

Li, H.L., Xia, H., Soliman, M., Frangopol, D.M. (2015) Bridge stress calculation based on the dynamic response of coupled trainbridge system, Engineering Structures 99: 334-345.

Liu, K., De Roeck, G., Lombaert, G. (2009) The effect of dynamic train-bridge interaction on the bridge response during a train passage, Journal of Sound and Vibration 325(1-2): 240-251.

Lu, N., Noori, M., Liu, Y. (2017) Fatigue reliability assessment of welded steel bridge decks under stochastic truck loads via machine learning, Journal of Bridge Engineering ASCE 22(1): 04016105-1-12.

Lu, Q., Zhu, J., Zhang, W. (2020) Quantification of fatigue damage for structural details in slender coastal bridges using machine learning-based methods, Journal of Bridge Engineering ASCE 25(7): 04020033-1-12.

Marquardt, D.W. (1963) An algorithm for least-squares estimation of nonlinear parameters. Journal of the Society for Industrial and Applied Mathematics 11(2): 431-441.

MATLAB. (2015) Computer Software; MathWorks: Natick, MA, USA.

Moon, H.S., Ok, S., Chun, P.J., Lim, Y.M. (2019) Artificial neural network for vertical displacement prediction of a bridge from strains (part 1): girder bridge under moving vehicles, Applied Sciences 9(14): 2881.

Moreu, F., Jo, H., Li, J., Kim, R.E., Cho, S., Kimmle, A., Scola, S., Le, H., Spencer, B.F., LaFave, J.M. (2015) Dynamic assessment of timber railroad bridges using displacements, Journal of Bridge Engineering ASCE 20(10): 04014114-1-12.

National Railway Administration. (2014) Code for design of High Speed Railway (in Chinese).

Neves, A.C., González, I., Leander, J., Karoumi, R. (2017) Structural health monitoring of bridges: a model-free ANN-based approach to damage detection, Journal of Civil Structural Health Monitoring 7: 689-702.

Newmark, N.M. (1959) A method of computation for structural dynamics, ASCE Journal of Engineering Mechanics Division 85(3): 67-94

Ozdagli, A.I., Liu, B., Moreu, F. (2018) Low-cost, efficient wireless intelligent sensors (LEWIS) measuring real-time referencefree dynamic displacements, Mechanical Systems and Signal Processing 107: 343-356.

Ribeiro, D., Calçada, R., Ferreira, J., Martins, T. (2014) Non-contact measurement of the dynamic displacement of railway bridges using an advanced video-based system, Engineering Structures 75: 164-180.

Ribes-Llario, F., Velarte-Gonzalez, J.L., Perez-Garnes, J.L., Real-Herráiz, J.I. (2016) Study of vibrations in a short-span bridge under resonance conditions considering train-track interaction, Latin American Journal of Solids and Structures 13: 1236-1249.

Rocha, J.M., Henriques, A.A., Calçada, R. (2012) Safety assessment of a short span railway bridge for high-speed traffic using simulation techniques, Engineering Structures 40: 141-154.

Rocha, J.M., Henriques, A.A., Calçada, R. (2014) Probabilistic safety assessment of a short span high-speed railway bridge, Engineering Structures 71: 99-111.

Salcher, P., Pradlwarter, H., Adam, C. (2016) Reliability assessment of railway bridges subjected to high-speed trains considering the effects of seasonal temperature changes, Engineering Structures 126: 712-724.

Shu, J.P., Zhang, Z.Y., Gonzalez, I., Karoumi, R. (2013) The application of a damage detection method using artificial neural network and train-induced vibrations on a simplified railway bridge model, Engineering Structures 52: 408-421.

Xia, H., Li, H.L., Guo, W.W., De Roeck, G. (2014) Vibration resonance and cancellation of simply supported bridges under moving train loads, Journal of Engineering Mechanics ASCE 140(5): 04014015-1-11.

Xia, H., Zhang, N., De Roeck, G. (2003) Dynamic analysis of high speed railway bridge under articulated trains, Computers and Structures 81: 2467-2478. 
Xia, H., Zhang, N., Guo, W.W. (2018) Dynamic interaction of train-bridge systems in high-speed railways: theory and applications, Springer.

Yang, Y.B., Yau, J.D., Wu, Y.S. (2004) Vehicle-bridge interaction dynamics: with applications to high-speed railways, World Scientific Publishing Company.

Yan, W.C., Deng, L., Zhang, F., Li, T.G., Li, S.F. (2019) Probabilistic machine learning approach to bridge fatigue failure analysis due to vehicular overloading, Engineering Structures 193: 91-99.

Yu, Z.W., Mao, J.F., Guo, F.Q., Guo, W. (2016) Non-stationary random vibration analysis of a 3D train-bridge system using the probability density evolution method, Journal of Sound and Vibration 366: 173-189.

Zhai, W.M., Cai, C.B., Guo, S.Z. (1996) Coupling model of vertical and lateral vehicle-track interactions, Vehicle System Dynamics 26(1): 61-79.

Zhai, W.M., Han, Z.L., Chen, Z.W., Ling, L., Zhu, S.Y. (2019) Train-track-bridge dynamic interaction: A state-of-the-art review, Vehicle System Dynamics 57: 984-1027.

Zhai, W.M., Xia, H. (2011) Train-track-bridge dynamic interaction: theory and engineering application, Science Press (in Chinese).

Zhang, N., Xia, H., Guo, W.W., De Roeck, G. (2010). A vehicle-bridge linear interaction model and its validation, International Journal of Structural Stability and Dynamics 10(2): 335-61.

Zhu, J., Zhang, W. (2018). Probabilistic fatigue damage assessment of coastal slender bridges under coupled dynamic loads, Engineering Structures 166: 274-285. 